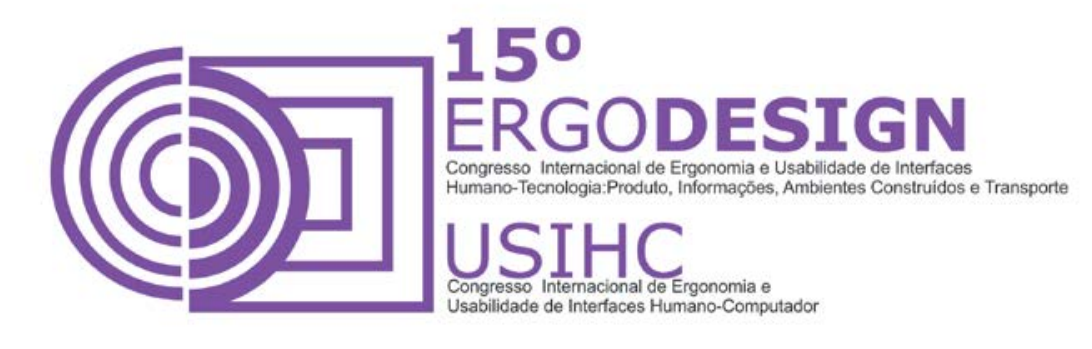

\title{
AVALIAÇÃO HEURÍSTICA DO MODELO FUNCIONAL DA LUMINÁRIA MODULAR LED
}

\author{
RODRIGUES, Yago W. (1); \\ OKIMOTO, Maria Lucia R. (2); \\ (1) UDESC, Graduado \\ e-mail: yagowr5@gmail.com \\ (2) UFPR, Doutora \\ e-mail: lucia.demec@ufpr.br
}

\begin{abstract}
RESUMO
O presente trabalho tem como objetivo avaliar o modelo funcional de luminária LED a partir de especificações heurísticas e ergonômicos. A análise do procedimento permitiu identificar e descrever as caraterísticas negativas e positivas da avaliação do modelo com os usuários em relação aos aspectos ergonômicos e de usabilidade, bem como propor recomendações para qualificar o produto em desenvolvimento. As informações obtidas com o estudo apontam uma dificuldade principal no processo que consiste na avaliação de um modelo funcional de média fidelidade.
\end{abstract}

\section{ABSTRACT}

This study aims to evaluate the LED lamp functional model from heuristics and ergonomic specifications. The analysis of the procedure has to identify and describe the positive and negative features of the model evaluation with users regarding ergonomics and usability, and provide guidelines to qualify the product under development. The information obtained from the study indicate a major difficulty in the process that involves the assessment of a functional model of average fidelity.

\section{INTRODUÇÃO}

O modelo é fruto de uma pesquisa maior intitulada Plataforma de luminária led para habitação de interesse social em nível de mestrado e desenvolvida pela Universidade Federal do Paraná 


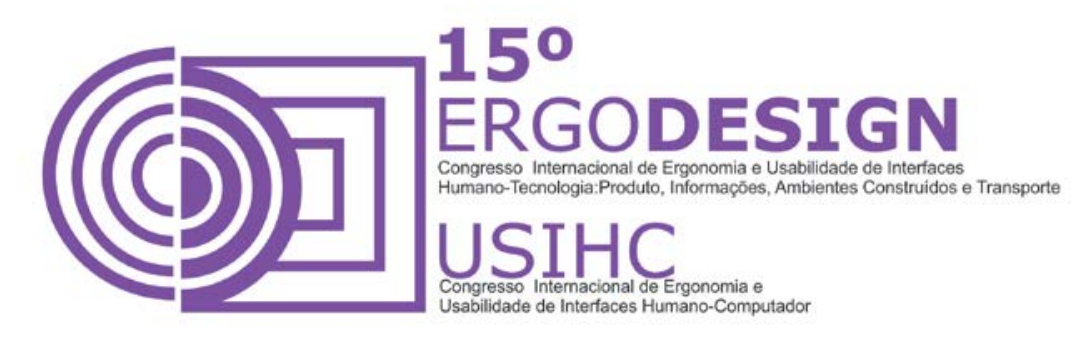

- UFPR com uma parceria entre o Núcleo de Design e Sustentabilidade e especialistas (SERBENA, 2013).

O produto a ser avaliado é uma luminária modular com tecnologia LED orientada a um conceito de sistema eco-eficiente, o modelo possui 1 base hexagonal, 3 módulos quadrados e interruptor conforme demostra a imagem 1 e 2. Seu conceito é a economia de energia através do uso consciente pelo usuário e o conforto lumínico na residência populares.

Conforme aborda Serbena (2013) a economia de energia permite que as famílias possuam um gasto inferior na conta de iluminação, podendo destinar este recurso para atender outras necessidades. O conforto lumínico está relacionado ao bem-estar do usuário e ao correto nível de luz presente no ambiente de modo a evitar a fadiga visual ou mesmo problemas de saúde devido à má iluminação em suas varias tarefas ao longo do dia:

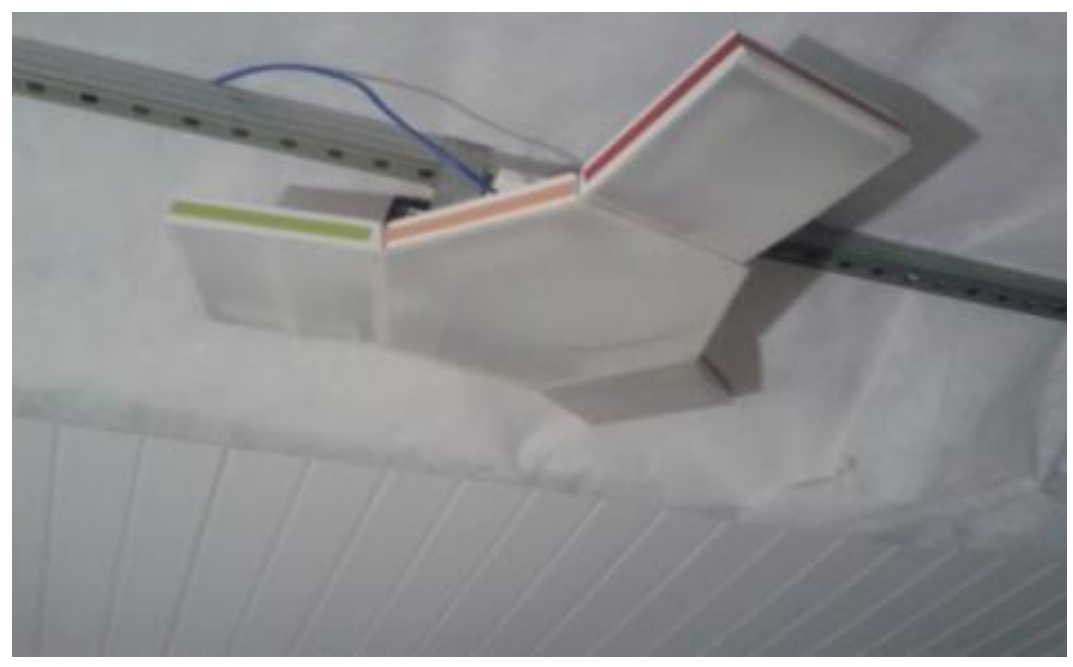

Imagem 1. Luminária LED instalada.

Os LEDs de potência selecionados para construção do modelo foram da empresa Seul Semicom Acriche, modelo AN4214 de 8 watts, AN3211 de 4 watts em 3300K e 5500K ( imagem2 ). O material do modelo funcional são chapas de aço, envolvendo o processo de corte e dobra, e acabamento em pintura epóxi. A luminária utiliza a saída da tomada padrão ABNT NBR 14136, devido a garantir a segurança para o usuário da ligação elétrica: 

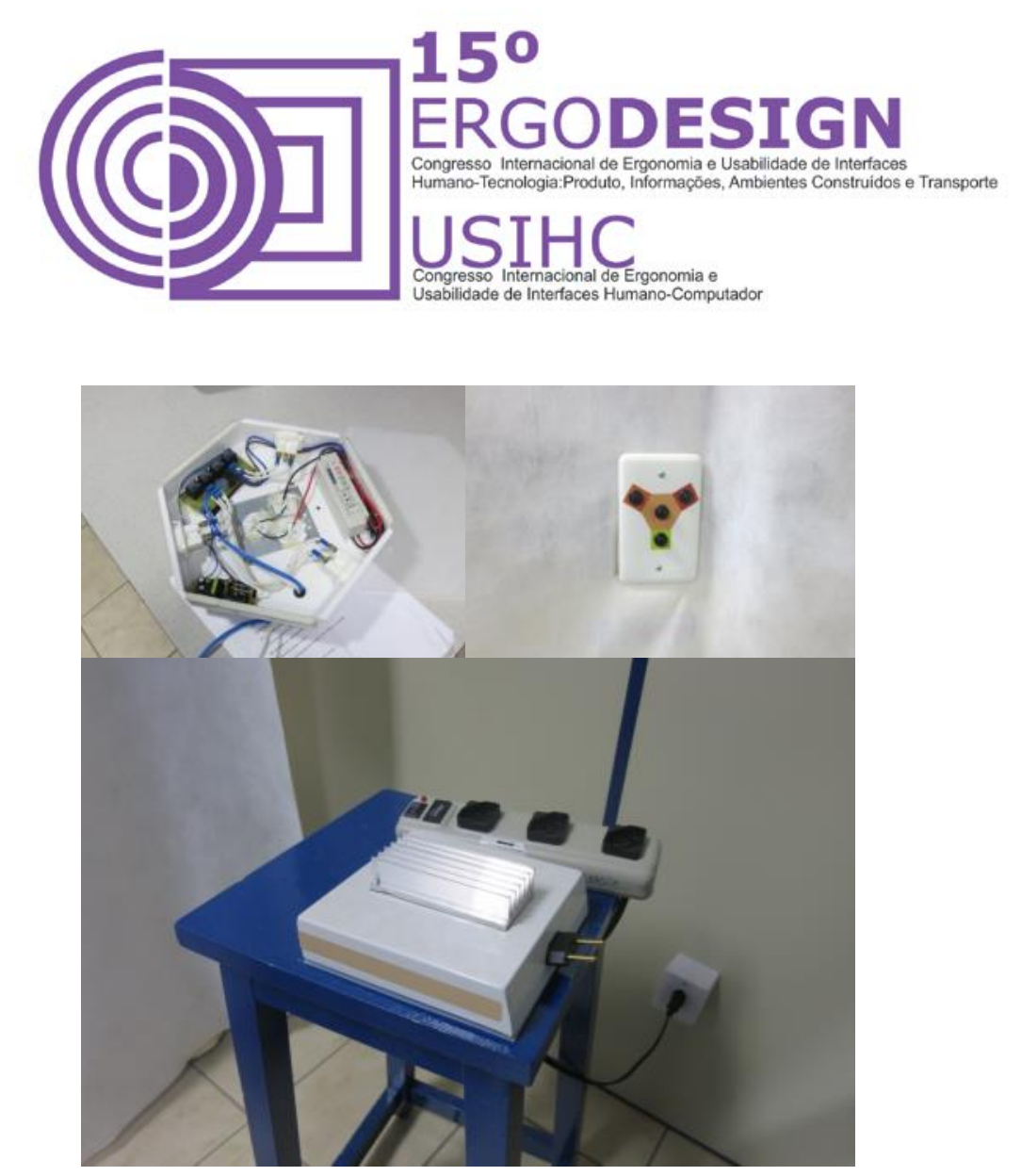

Imagem 2. Base, Interruptor e módulo.

O sistema de iluminação é baseado numa plataforma central hexagonal com três suportes para adição dos módulos LED (compostos por dissipador e chipled). Eles também podem ser ligados separadamente criando uma escala de luminosidade no ambiente através do interruptor conforme desejado pelo usuário (imagem 3):
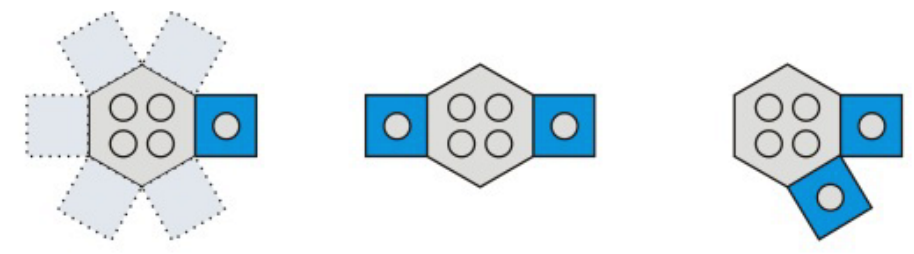

Imagem 3. Conceito de funcionamento do modelo LED. Fonte: Adaptado SERBENA, 2013.

Assim, o projeto tem com ideia principal a versatilidade nas necessidades. Por possuir uma boa taxa de variação de iluminância, a luminária pode ser utilizada para diversos fins em diferentes cômodos domésticos. Há também a vantagem de seletivamente acender os módulos, de forma a receber a quantidade de luz ambiente necessária e também evitar o sobre gasto energético. 


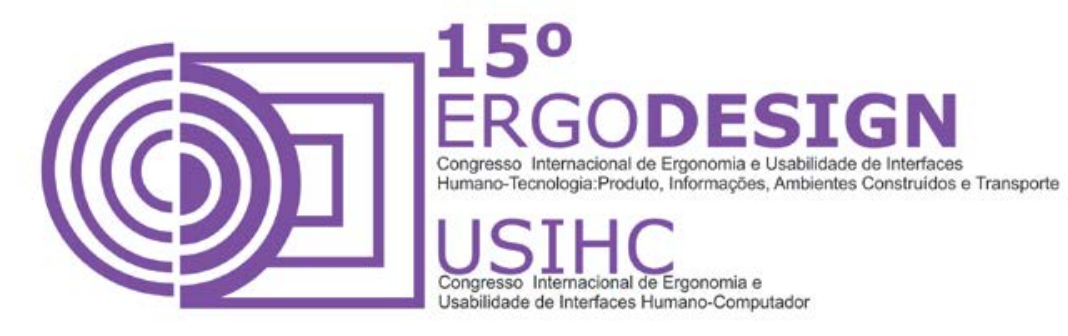

Conforme a imagem 4, é demostrado também os detalhes do dissipador, pois a tecnologia LED produz menos calor que uma lâmpada convencional, porém segundo o projeto é necessário ser dissipada para atrás dos módulos, evitando o aumento de temperatura interna na qual pode levar a acidentes:
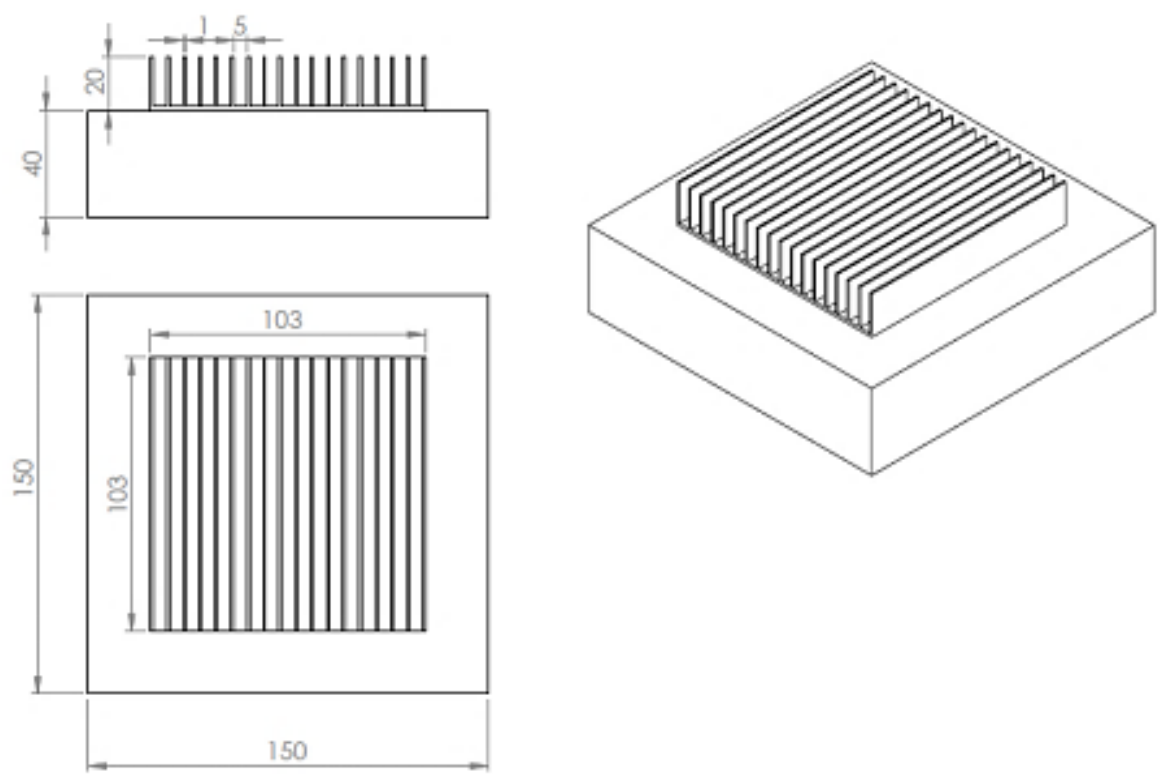

Imagem 4. Dimensões do módulo quadrado (sem o plug de encaixe)

\section{METODOLOGIA}

Por se tratar de um modelo funcional em fase de pesquisa a avaliação é considerada formativa que se refere à identificação e correção de problemas, com vistas a melhorar o produto no processo de desenvolvimento (MAGUIRE, 2001). A pesquisa tem uma abordagem centrada no usuário (DCU), ou seja, que considera a participação dos usuários em uma ou mais etapas ao longo do processo projetual, no aperfeiçoamento de produtos.

A metodologia consiste em uma avaliação heurística com 5 especialistas aplicando-se a análise das heurísticas infringidas por Nielsen e Molich (1990) e também os critérios ergonômicos infringidos segundo Bastien e Scapin (1993) sobre o modelo funcional.

Em cada fase os especialistas deveriam antes de responder o questionário ou a entrevista (em anexo), passar pelo seguinte processo para explorar o produto e o ambiente:

1. Assinar o termo de consentimento livre e esclarecido (em anexo). 


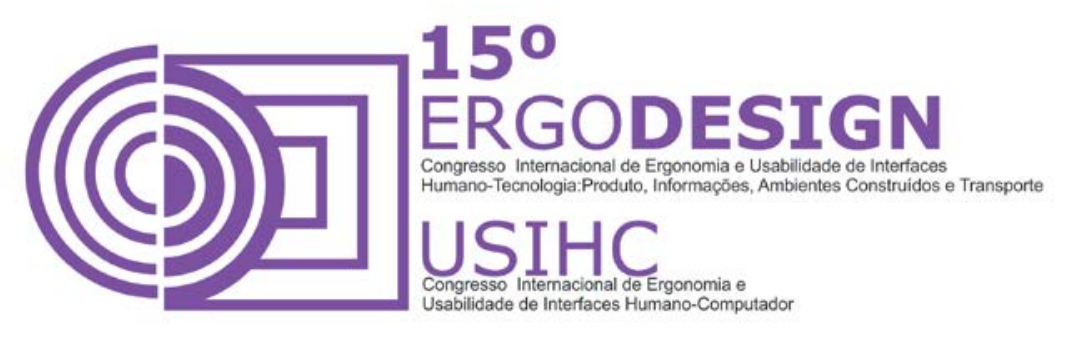

2. Manusear o modelo funcional sem ser instalado (base, módulos e interruptor).

3. Ligar e desligar a luminária instalada através do interruptor (ligar a base e cada módulo) e observar cada tipo de iluminação. instalada.

4. Utilizar melhor iluminação para assistir TV e ler um livro com a luminária de teto ligado.

5. Utilizar melhor iluminação para assistir TV e ler um livro com apenas um módulo

Um desafio foi realizar uma avalição mais próxima do contexto real, devido ao modelo de média fidelidade que enviesaria a realização de um teste de usabilidade, ou seja, algumas propriedades são diferentes da versão final, como por exemplo, o material, textura e o peso.

\section{RESULTADOS E DISCUSSÃO}

\subsection{Avaliação Heurística}

Para a realização da fase de avaliação heurística foram convidados 5 sujeitos, estudantes do curso de pós-graduação em design (02 mestrandos, 2 mestres, e 1 doutorando) que já cursaram a disciplina de usabilidade do Programa de Pós graduação em Design e que atuam na pesquisa dentro da área de usabilidade. Os 5 indivíduos foram convidados a participar voluntariamente do teste, em dia e hora pré-determinado. Cada teste foi realizado individualmente, sem contato com os demais sujeitos. A seguir são descritas cada uma das perguntas efetuados aos sujeitos e o resultado foi compilado em tabelas, descritas junto a cada item.

Após os resultados obtidos da avaliação heurística realizadas por especialistas, foi realizada a somatória de todos os pontos sobre o produto para melhor visuzalição das questões aplicadas, bem como melhor entendimento das variáveis. Dessa forma avaliou-se o produto como um todo, e não de forma específica para cada item (interruptor, base e módulos).

Os resultados obtidos busca entender a fonte dos problemas de usabilidade relacionados à luminária. Referente às heurísticas infringidas como mostrado no gráfico 55 , todas as heurística foram infringidas mais do que 4 vezes o que mostra um problema geral na luminária, na qual a que representa maior concentração foi a flexibilidade e eficiência no uso, sendo 19 vezes citada, cerca de $17 \%$ do total.

Assim, percebe-se um problema na falta de flexibilidade do produto, apesar de ser uma luminária multifuncional (que reduz a energia com o uso consciente), entretanto, não proporciona de forma eficiente à questão do uso, o que leva o usuário há gastar muito tempo em tarefas simples ou até desistir da mesma.

A segunda mais citada foi à prevenção de erros, com 17 citações (15 \%), o que demostra falta de avisos ou de segurança do produto, sem o feedback imediato do sistema, interligando 0 


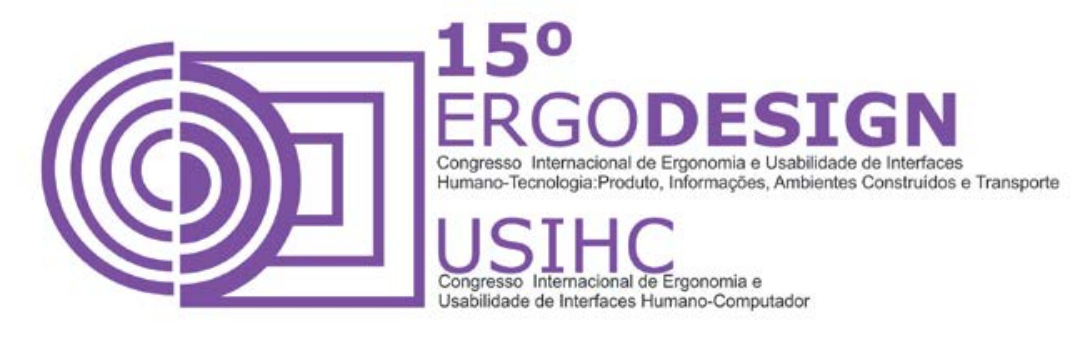

usuário-sistema - atividade numa melhor relação de comunicação. A terceira é a visibilidade do sistema notada 15 vezes com cerca de $13 \%$ do total.

Esse dado, demostra problemas relacionados à comunicação do produto, na dificuldade da interface física em mostrar opções, forma ou solução para a tarefa ser realizada com sucesso. Ademais, como não há interação digital talvez fique mais difícil comunicar e visualizar mais possibilidades ao uso, como a interação de modificar a intensidade, cor, projeção:

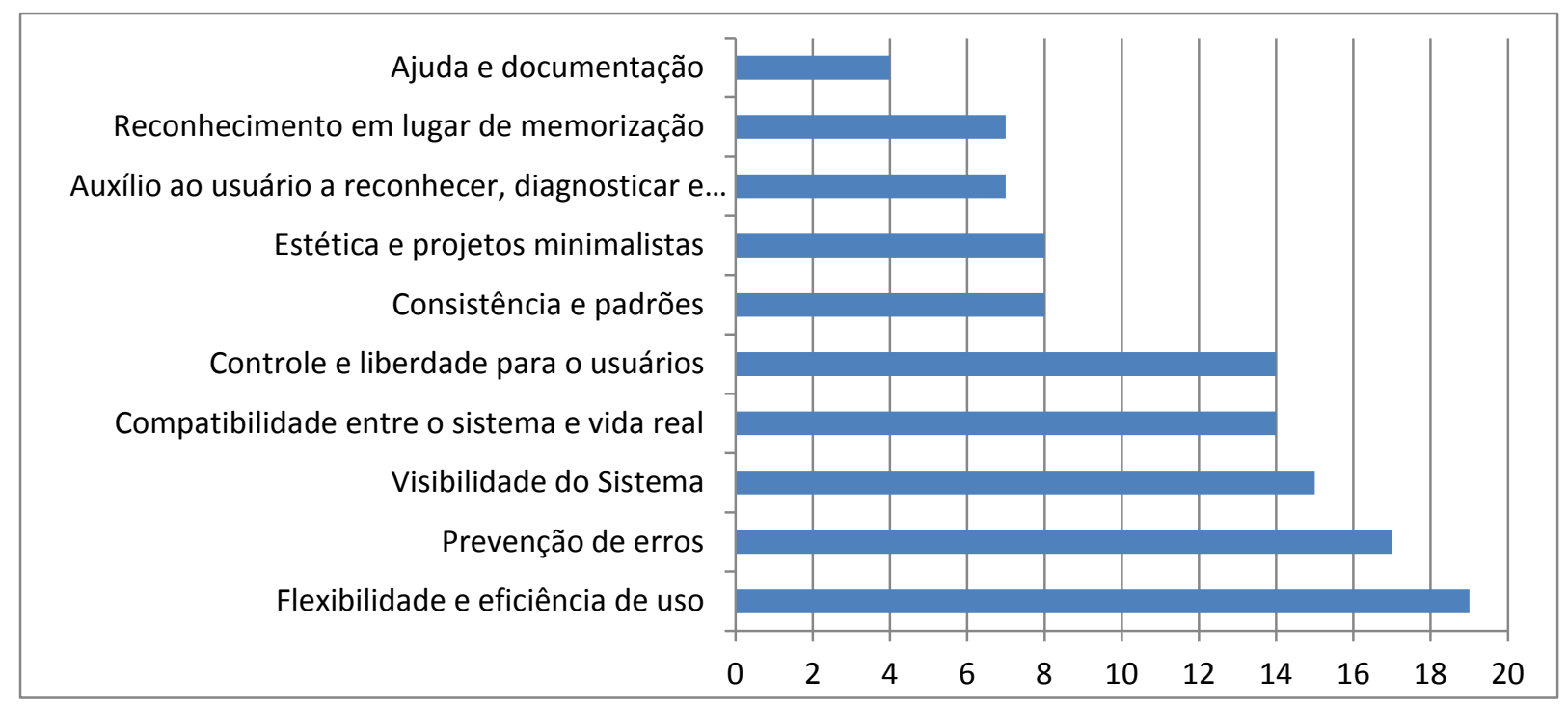

Gráfico 1. Somatório das heurísticas infringidas.

Referente aos critérios ergonômicos infringidos totais da luminária, conforme representa o gráfico 56, todos ao menos uma vez foram infringidos, com predominância na gestão de erros (15 citações com 17,6 \%) o que está relacionado com a heurística de prevenção de erros.

Nessa ordem, a legibilidade e a flexibilidade do produto mostram-se empatados em segundo com 16,4 \% (14 citações), um resultado bem próximo a gestão de erros. Assim, da mesma forma é correlacionado com o resultado geral das heurísticas (visibilidade do sistema e flexibilidade). O que enfatiza a origem dos 3 problemas mais citados: 

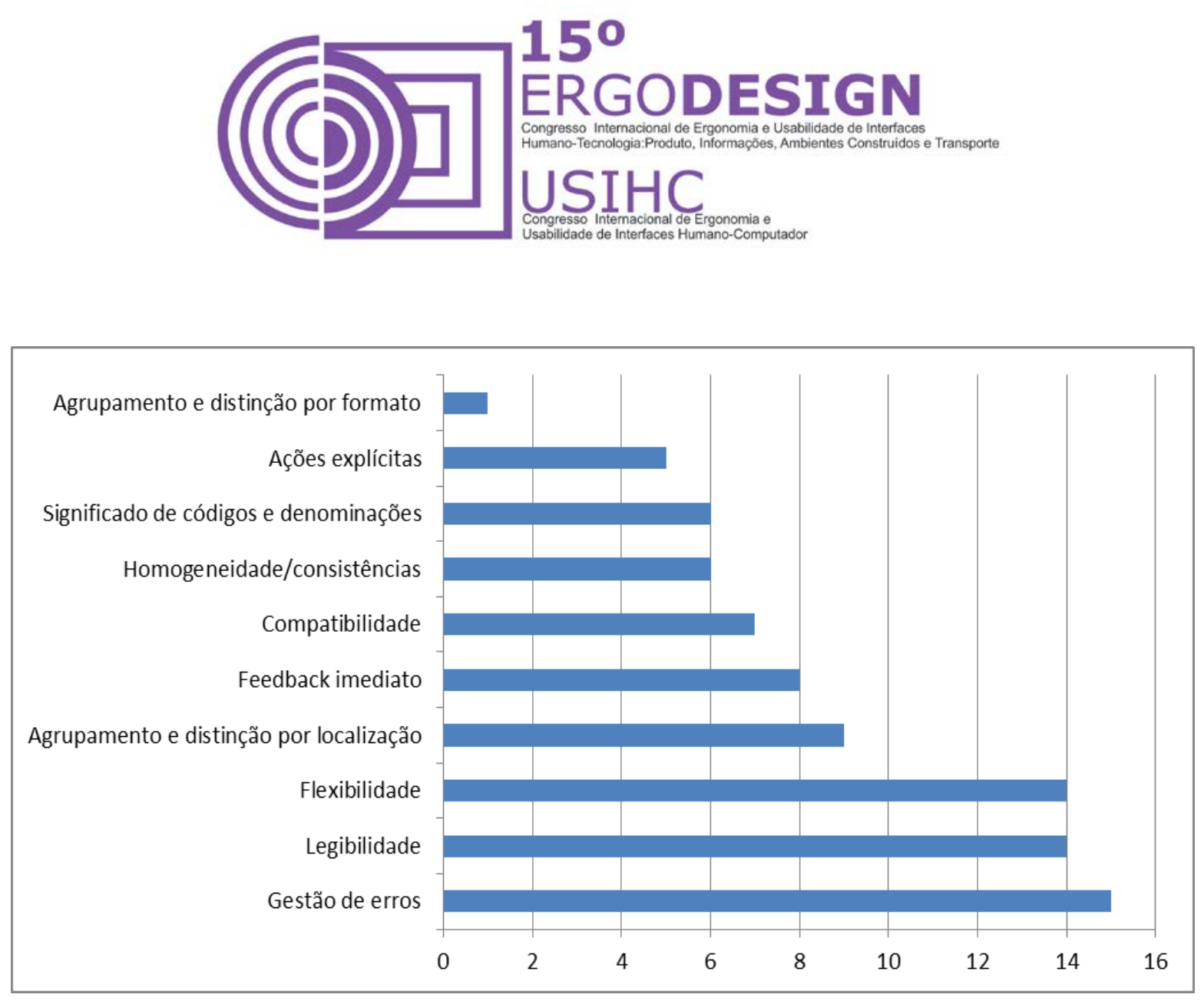

Gráfico 2. Somatório dos critérios ergonômicos infringidos.

Sobre de nível de severidade geral da luminária, há ponderação na média da severidade, conforme demostra o gráfico 57 (maiores gráficos concentrados no meio). Os resultados estão relacionados com a fase de desenvolvimento do modelo funcional, que está em o projeto está processo formativo. Que provavelmente com um protótipo ou modelo mais leve ou já sem sua fase final, teria essa passagem de severidade do ponto médio para o "muito pouco" (item 1).

Dessa forma, há concentração no item 2 e 3 (31,14\%), o que prevalece uma preocupação média (entre pouco e muito severo) dos problemas identificados no produto, que não devem ser desconsiderados, pois somados passam da metade do total $(62,28 \%)$ : 

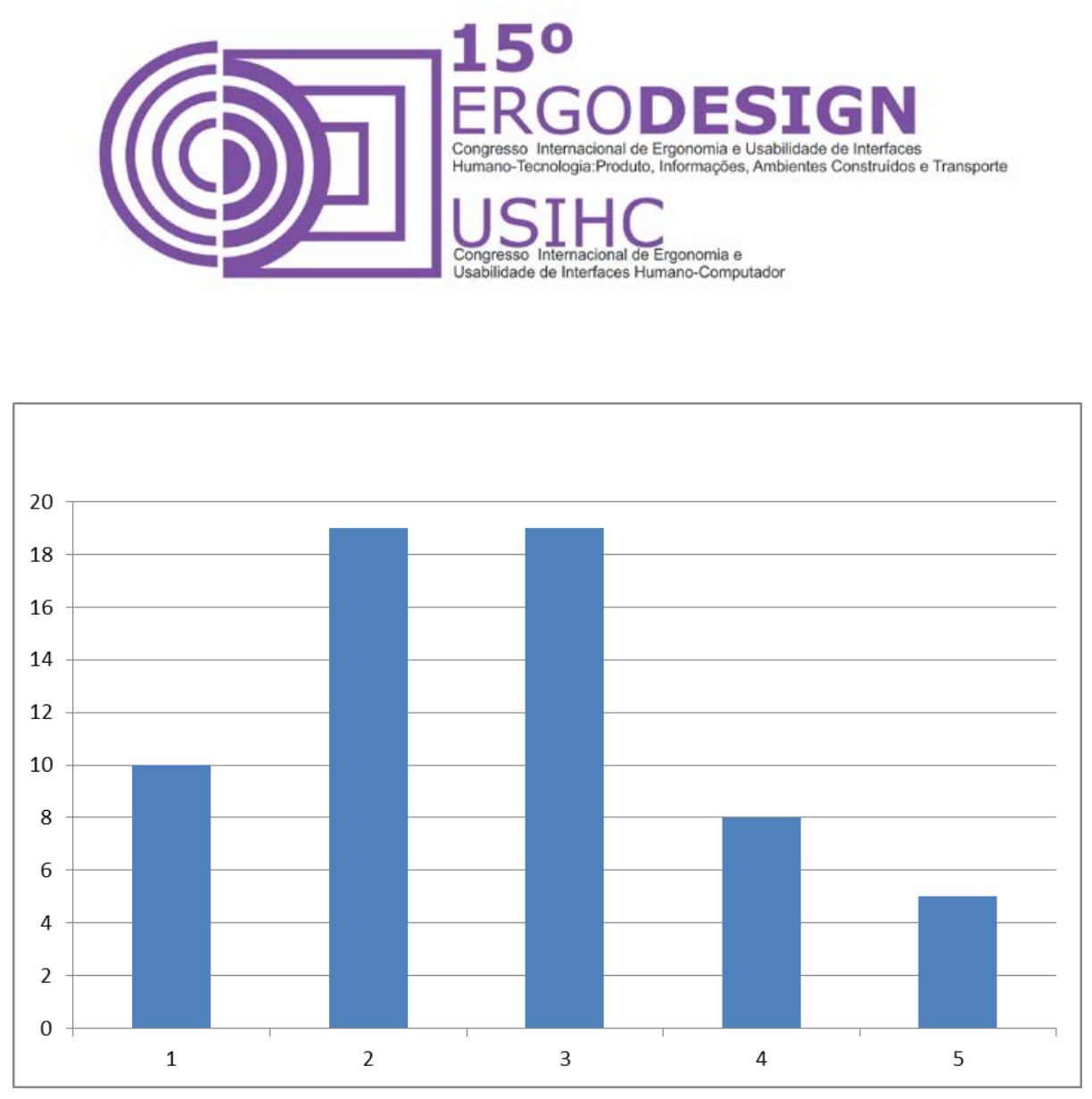

Gráfico 3. Somatório do nível de severidade dos problemas observados.

Referente aonde se terá implicações negativas na usabilidade para o produto, de forma geral foi identificada como ponto principal a satisfação do usuário ao utilizar a luminária com 42,85 \% (30 ocorrências), em segundo lugar a eficácia (34,28 \% - 24 ocorrências) e por último a eficiência com 24,28\% (17 ocorrências).

Assim, a origem está mais direcionada para a satisfação, ou seja, a reação do usuário em relação com o produto, gostos e desgostos ao uso. A eficácia prevalece a eficiência, mostrando que o usuário vai cometer mais erros relacionados a fazer tarefas erradas do que gastar mais tempo nas tarefas, ou seja, tem mais uma tendência a tentativa e erro, do que gastar mais tempo em uma determina tarefa: 

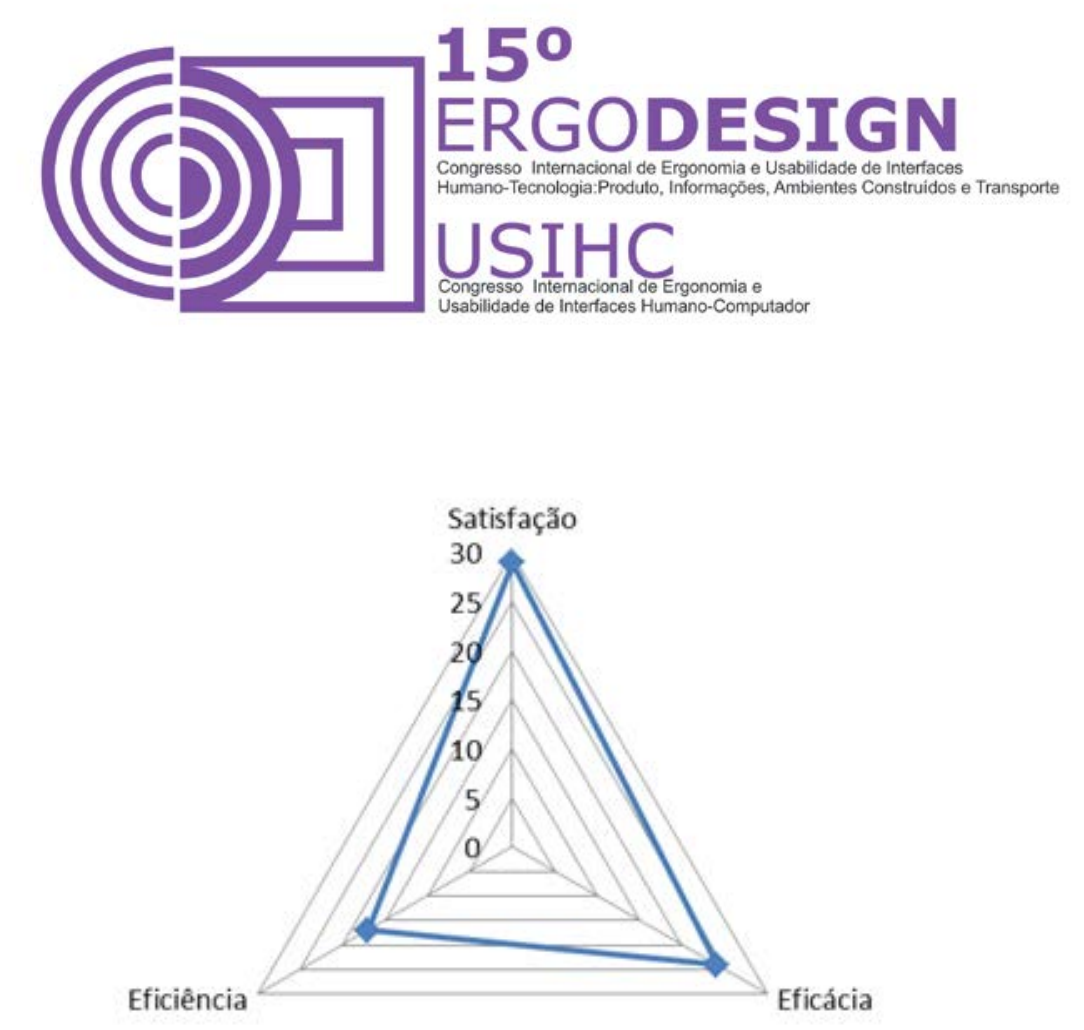

Gráfico 4. Somatório das dimensões onde se terá implicações negativas.

\section{CONCLUSÃO}

Conforme os dados obtidos pelo procedimento adotado, observamos a eficácia dos métodos propostos, pois a avaliação considerou aspectos relacionados ao design centrado nos usuários, bem como sua experiência em relação ao uso, no qual termos generalistas foram melhor discutidos e especificados.

$\mathrm{Na}$ avaliação com os especialistas foi levantando as principais fontes dos problemas perante as heurísticas e critérios ergonômicos infringidos, essa mostrou preocupações relacionadas principalmente com a flexibilidade do uso, gestão de erros e legibilidade do sistema; sendo identificado de forma natural colocando-se no lugar do usuário.

A avaliação identificou que a luminária precisa de mudanças de flexibilidade de uso e que isso afeta drasticamente a satisfação do usuário, alterações em relação ao tempo de reconhecimento da interface precisa ser diminuído, facilitando operações de fácil memorização com o interruptor, com botões mais intuitivos ou digitais. Uma opção também seria adotar desenhos da própria luminária e manter o layout já proposto com cores mais contrastantes. Em relação aos módulos e a base, com a mudança do material para um polímero, irá afetar diretamente o peso do produto final, facilitando os encaixes instáveis. Também seria interessante deixar a luz mais suave para a saída da luz.

Em suma, a pesquisa releva a elevada carga cognitiva para o usuário entender o procedimento, bem como, o sistema se mostra excessivamente burocratizado para fazer uma ação simples (acender uma lâmpada). Além disso, o formato não comunica a economia de energia. 0 sistema de código cromático e posicionamento não se mostra eficaz.

Outro aspecto identificado é a inconsistência entre a localização dos interruptores e dos módulos. Os mesmos se apresentam com orientações espaciais diferentes e, portanto, a 


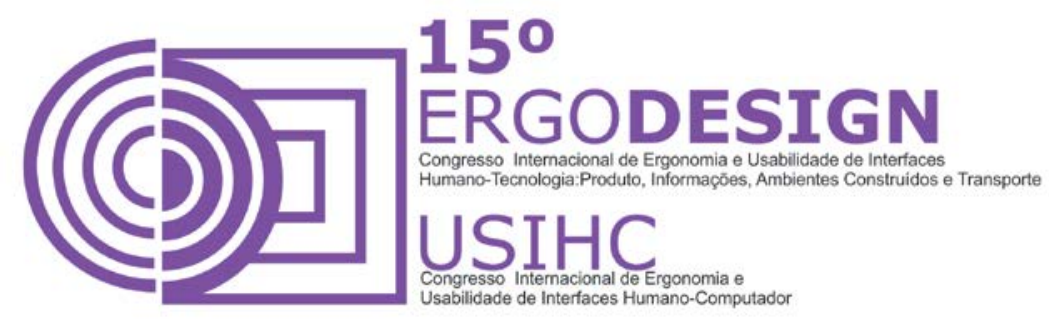

percepção do usuário poderá mudar entre uma leitura horizontal e vertical. Assim, rever a apresentação gráfica do painel de botões, permite maior fidelidade na relação com a visão do usuário com relação ao produto.

\section{AGRADECIMENTOS}

Agradecemos ao Conselho Nacional de Desenvolvimento Científico e Tecnológico (CNPq), a Coordenação de Aperfeiçoamento de Pessoal de Nível Superior (CAPES) e ao Programa de Pós-Graduação em Design (PPGDesign).

\section{REFERÊNCIAS BIBLIOGRÁFICAS}

BASTIEN, C. e SCAPIN, D. Ergonomic Criteria for the Evaluation of Human Computer Interfaces. INRIA, 1993.

MAGUIRE, M. Methods to support human - centred design. Int. J. Human Computer Studies, vol55, 2001. p. 587-634.

NIELSEN, J., Molich, R. Heuristic evaluation of user interfaces. Proceedings of the SIGCHI conference on human factors in computing systems: Empowering people. Seattle, WA, USA. Abril, 1990.

SERBENA, Henrique José. Plataforma de luminária LED para habitação de interesse social. $201 \mathrm{f}$. Dissertação (Mestrado em Design). UFPR, fevereiro, 2013. 